\title{
EXPLORING THE APPLICATION OF VOLUNTEERED GEOGRAPHIC INFORMATION TO CATCHMENT MANAGEMENT: A SURVEY APPROACH
}

\author{
D. R. Paudyal ${ }^{\text {ab }}$, K. McDougall ${ }^{\text {ab }} \&$ A. Apan ${ }^{\text {ab }}$ \\ ${ }^{a}$ Faculty of Engineering and Surveying \\ ${ }^{\mathrm{b}}$ Australian Centre for Sustainable Catchments \\ University of Southern Queensland, Queensland 4350, Australia \\ (paudyal, mcdougak, apana)@usq.edu.au
}

\section{Commissions IV, WG IV/2}

KEY WORDS: Volunteered Geographic Information, Spatial Information, Spatial Data Infrastructure, User-generated Content, Natural Resource Management, Catchment Management

\begin{abstract}
:
The participation and engagement of grass-root level community groups and citizens for natural resource management has a long history. With recent developments in ICT tools and spatial technology, these groups are seeking a new opportunity to manage natural resource data. There are lot of spatial information collected/generated by landcare groups, land holders and other community groups at the grass-root level through their volunteer initiatives. State government organisations are also interested in gaining access to this spatial data/information and engaging these groups to collect spatial information under their mapping programs. The aim of this paper is to explore the possible utilisation of volunteered geographic information (VGI) for catchment management activities. This research paper discusses the importance of spatial information and spatial data infrastructure (SDI) for catchment management and the emergence of VGI. A conceptual framework has been developed to illustrate how these emerging spatial information applications and various community volunteer activities can contribute to a more inclusive spatial data infrastructure (SDI) development at local level. A survey of 56 regional NRM bodies in Australia was utilised to explore the current community-driven volunteer initiatives for NRM activities and the potential of utilisation of VGI initiatives for NRM decision making process. This research paper concludes that VGI activities have great potential to contribute to SDI development at the community level to achieve better natural resource management (NRM) outcomes.
\end{abstract}

\section{INTRODUCTION}

\subsection{Background}

The participation and engagement of grass-root level community groups and citizens for natural resource management has a long history in Australia. Since 1990, there have been many attempts by State governments to involve communities in environmental projects such as Salt-Watch, Water-Watch and Landcare projects with communities providing volunteer support to state government organisations (Carr, 2002). These community volunteer activities have been successful in achieving better environmental outcomes and acknowledgement by government agencies. The local environmental knowledge of these groups can also be used for spatial information collection and management. Traditionally, spatial information was managed and controlled by government agencies for NRM activities. Recent developments in ICT tools and spatial technology have provided community groups with a new opportunity to manage the natural resource data. There is a significant amount of spatial information collected/generated by land care groups, land holders and other community groups at grass-root level through these volunteer initiatives. Government organisations are also employing volunteered input into their mapping programs. It has opened the new avenue to manage and utilise spatial data for natural resource management.

\subsection{Spatial Information and SDI for Natural Resource Management}

Spatial data underpins decision-making for many disciplines (Clinton, 1994; Gore, 1998; Longley et al., 1999; Rajabifard et al., 2003) including catchment management. Reliable information infrastructure is needed to record the environmental, social and economic dimensions of natural resource management and to support appropriate decision making and conflict resolution (Paudyal et al., 2009). Within information infrastructure, spatial data infrastructure (SDI) is a framework for linking users with providers of spatial information. SDI comprises the people, policies and technologies necessary to enable the use of spatially referenced data through all levels of government, the private sector, nonprofit organisations and academia. (ANZLIC, 2003).

SDI can facilitate access to the spatial data and services through improving the existing complex and multi-stakeholder decision-making processes (Feeney, 2003; McDougall and Rajabifard, 2007). Moreover, it can facilitate (and coordinate) the exchange and sharing of spatial data between stakeholders within the spatial information (SI) community. A preliminary step toward achieving decision-making for catchment management has been the increasing recognition of the role of SDI to generate knowledge, identify problems, propose alternatives and define future courses of action (Paudyal and McDougall, 2008). In recent years, many countries have spent considerable resources on developing SDI to manage and utilise their spatial data assets more efficiently, reduce the 
costs of data production and eliminate the duplication of data acquisition efforts (Masser, 2005; Rajabifard et al., 2003).

Traditionally, state government organisations were the custodians of spatial information necessary for the catchment decisions whilst regional NRM bodies were just the users of spatial information (Paudyal et al., 2011). The management of spatial data and development of SDI was dominated by mapping agencies, government agencies and spatially elite professionals. The easily accessible and available spatial technology and products like Google Earth, hand-held navigation systems, web 2.0 technologies, and social media provides the way for grass-root citizens and community groups with no prior experience in spatial technologies to contribute for spatial information management and SDI development. Volunteered Geographic Information (VGI) is one of the emerging areas within SDI domain where the spirit of volunteerism of community organisations can be utilised for spatial information collection and management. Government organisations are also employing volunteered input to their mapping programs. The following section discusses VGI and it's growing recognition.

\subsection{Emerging Spatial Information Application Area: Volunteered Geographic Information (VGI)}

A number of authors (Goodchild, 2008; Elwood, 2008; Goodchild, 2007; Kuhn, 2007; Coleman, 2010; McDougall, 2010) have begun to explore the application volunteered geographical information (VGI) for spatial information management. However, the utilisation of VGI for SDI development is still a new area. The term VGI was first used by Michael Goodchild to describe the diverse practices of observing, collecting and producing geographic information by citizens with no formal expertise in the area (Goodchild, 2007). The first research specialist meeting on VGI was organised under the auspices of NCGIA, Los Alamos National Laboratory, the Army Research Office and The Vespucci Initiative and brought researchers around the globe to discuss potential of VGI for spatial information management. Coleman (2010) explored how the concept of VGI fitted within SDI. The utilisation of VGI for spatial information collection and updating is now widely used by OpenStreetMap, TeleAtlas, NAVTEQ and Google Maps. Government organisations have now also realised the power of VGI and crowd sourcing and are interested in utilising these technologies for SDI development. U.S. Geological Survey was an early examiner of this technology. State governments in Victoria (Australia) and North-Rhine Westphalia (Germany) are two good examples of employing volunteered input to their mapping programs in the government sector (Coleman, 2010).

\subsection{Conceptual Framework}

If we observe from a theme perspective, catchment management is about management of land, water, biodiversity, coast and marine themes. There are both top-down and bottomup approaches exist for catchment management. Government organisations are leading from a top-down approach and the activities of community/ volunteer organisations are bottom-up. Spatial information plays an important role for better catchment outcomes. Basically two types of spatial data can be utilised for catchment management. State government organisations and mapping agencies are the custodians of authoritative spatial and community volunteer organisations can contribute for volunteered geographical information (VGI). Spatial data is one of the components of spatial data infrastructure (SDI). SDI can provide improved access, share and use of spatial and contribute for better catchment outcomes. Figure 1 illustrates the conceptual framework of how the spatial data infrastructure and catchment management activities are interlinked and how volunteered geographic information can contribute for catchment management activities (Figure 1).

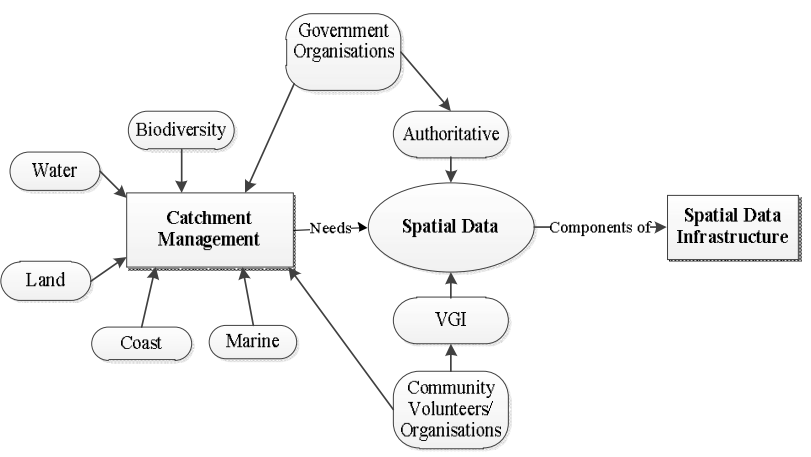

Figure 1. Conceptual framework

The aim of this paper is to explore the possible utilisation of volunteered geographic information (VGI) for catchment management activities. A survey was distributed to the 56 regional NRM bodies/catchment management authorities across Australia to examine community-driven volunteer activities and motivation factors and explore the applicability of easily accessible spatial products and VGI for catchment management activities.

\section{METHODS}

\subsection{The Study}

The study for this research is fifty-six regional NRM bodies whose boundary is based on catchments or bioregions (Figure 2).

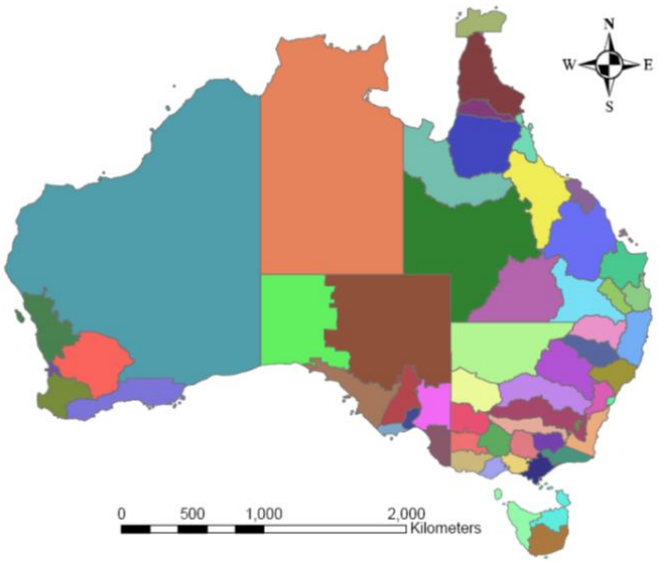

Figure 2. NRM regions boundary 


\subsection{Data Collection and Analysis Methods}

Axinn and Pearce (2006) suggested five key data collection strategies which are survey, case study, semistructured/unstructured interviews, focus groups, observations, and historical/archival research. A national survey of 56 regional NRM bodies was considered to be the most appropriate method for data collection. The majority of questions were closed and categorical type questions and measured on a five point Likert scale. The questionnaire was taken between June 2010 and September 2010. A total of 56 valid responses were received to the on-line questionnaire giving an overall response rate of $100 \%$. The online questionnaire was designed such that the data from the questionnaire was automatically collected into an Excel spread sheet via a web server. This eliminated the possibility of errors in coding and transcription and accelerated transferring data into data analysis software. For quality control purposes, the raw data were reviewed and cleaned up before feeding into statistical software.

The statistical analysis of the survey results was undertaken in the SPSS statistics package. The profile of respondents is tabulated in Figure 3, with the largest group of respondents being GIS officers, with other respondents including staff who were directly or indirectly involved with spatial information management or the GIS operations of the NRM body.

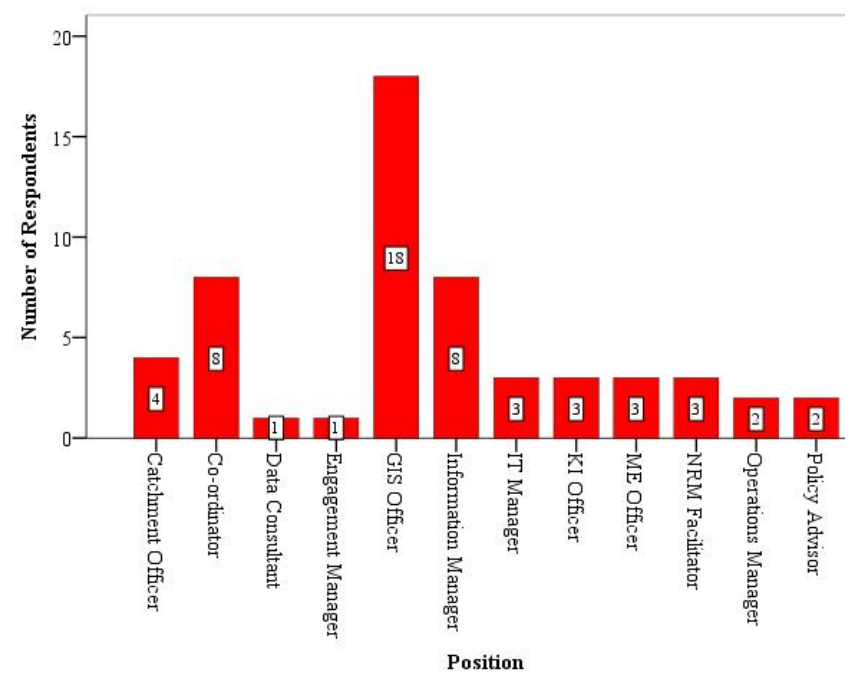

Figure 3. Profile of respondents (by position)

\section{RESULTS}

This section discusses the key findings from survey and discusses the potential of VGI for natural resource management.

\subsection{Catchment Management Issues and Role of Spatial Information}

There are disparities among regional NRM bodies regarding the catchment management issues on which they focus. However, we tried to explore the main catchment issues at national scale. Table 1 shows the top ten catchment management issues at the national level in Australia. The highest priorities include Healthy Habitat \& Biodiversity Conversion, Community Capacity Building \& Indigenous
Engagement, Pest Animal \& Weed Management, Disaster Management, and Water Resource Management. The Grazing Land and Property Management, Aboriginal NRM, and Cultural Heritage are the less focussed issues.

\begin{tabular}{|l|l|l|}
\hline Rank & $\begin{array}{l}\text { Catchment Management } \\
\text { Issues }\end{array}$ & Frequency \\
\hline 1 & $\begin{array}{l}\text { Healthy Habitat and Biodiversity } \\
\text { Conservation }\end{array}$ & 38 \\
\hline 2 & $\begin{array}{l}\text { Community Capacity Building } \\
\text { and Indigenous Engagement }\end{array}$ & 27 \\
\hline 3 & $\begin{array}{l}\text { Pest Animal and Weed } \\
\text { Management }\end{array}$ & 29 \\
\hline 4 & $\begin{array}{l}\text { Disaster Management (Fire } \\
\text { Mapping, Floodplain, Land } \\
\text { erosion, etc.) }\end{array}$ & 24 \\
\hline 5 & $\begin{array}{l}\text { Water Resource Management } \\
\text { Land Use Planning and Soil }\end{array}$ & 23 \\
\hline 6 & $\begin{array}{l}\text { Climate Change and Marine } \\
\text { Mastal anagement (estuarine and near } \\
\text { shore) }\end{array}$ & 5 \\
\hline 7 & $\begin{array}{l}\text { Grazing Land and Property } \\
\text { Management }\end{array}$ & 4 \\
\hline 8 & $\begin{array}{l}\text { Aboriginal NRM and Cultural } \\
\text { Heritage }\end{array}$ & 3 \\
\hline
\end{tabular}

Table 1. Main catchment management issues

When asked to identify the role that spatial information can play in addressing catchment management issues listed in Table 1, it was interesting to observe that about $60 \%$ of the regional NRM bodies responded that spatial information can play a very significant role whilst the remaining $40 \%$ of the organisations responded that it can play a significant role (Figure 4). Not a single organisation responded that they were not aware about the role of spatial information in addressing catchment management issues. This response also provides scope to support the development of spatial data infrastructure at regional level (catchment level) to address catchment management issues and facilitate better catchment outcomes.

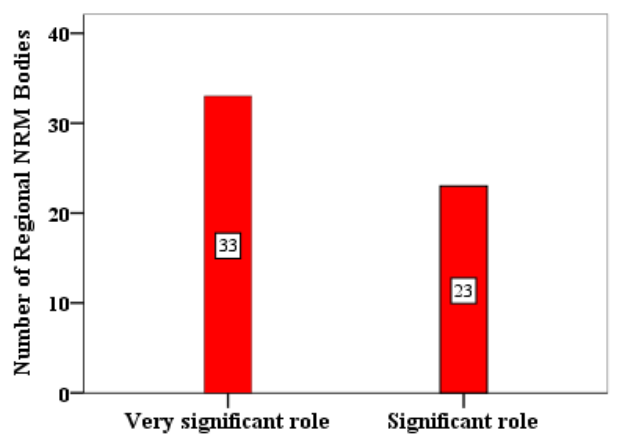

Figure 4. Role of spatial information to address catchment management issues

\subsection{Spatial Capacity of Regional NRM Bodies}

The majority (80\%) of regional NRM bodies identified themselves as being both a user and provider of spatial information and the remainder as being a user. Not a single 
NRM body identified themselves as a sole spatial data provider (Figure 5).

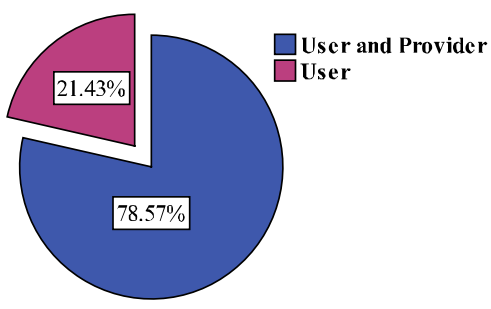

Figure 5. Breakdown of user/provider of spatial information

The main users of spatial information generated or value-added by these regional NRM bodies are the community organisations (landcare, watercare, birdwatch, etc.), land owners and indigenous groups.

\subsection{Community-driven Volunteer Initiatives and Motivation Factors}

This study also identified the major communitydriven/volunteer initiatives which are associated with catchment management. There are more than twenty volunteer activities spread over all the themes such as land, water, biodiversity, coast, and marine for catchment management. The Landcare, Waterwatch, Coastcare, Land for wildlife, Birdwatch, Vegewatch, and indigenous groups are the major one as illustrated in Figure 6.

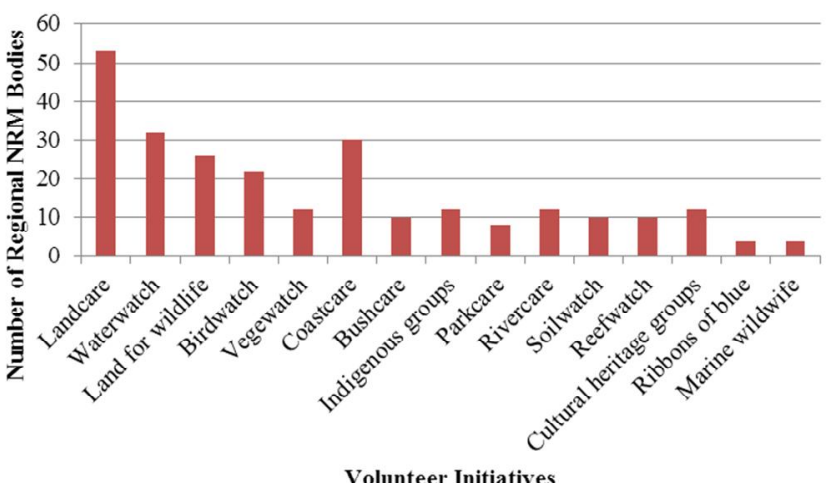

Figure 6. Community volunteer initiatives for catchment management activities

The motivation factors for these volunteer activities were identified and ranked them according to the responses as shown in Table 2. The top three motivation factors are awareness and concern regarding environmental benefits, long standing love of the land and/or water, and social interactions/benefits.

\begin{tabular}{|l|l|}
\hline Rank & Motivation Factors \\
\hline 1 & $\begin{array}{l}\text { Awareness and concern regarding } \\
\text { environmental benefits }\end{array}$ \\
\hline 2 & Long standing love of the land and/or water \\
\hline 3 & Social interactions/benefits \\
\hline 4 & Self-esteem/Desire to serve community \\
\hline 5 & Personal benefits \\
\hline 6 & Having fun/Getting hand dirty \\
\hline
\end{tabular}

\begin{tabular}{|l|l|}
\hline 7 & Cultural obligation/Spiritual connectivity \\
\hline
\end{tabular}

Table 2. Motivation factors for volunteer activities

\subsection{Awareness, frequency of use, and applicability of VGI}

The majority (95\%) of the regional NRM bodies/CMAs advised that they are aware of freely available/accessible spatial products e.g. Google Maps, OpenStreetMap, Wikimapia, etc. and VGI activities for their work needs.

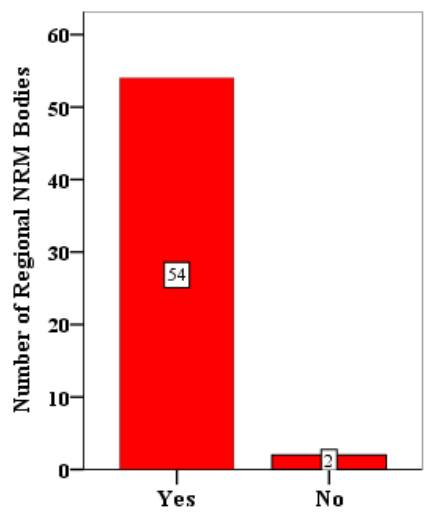

Figure 7. Awareness of VGI and freely available/accessible spatial products

However, the utilisation of these products for catchment management activities is infrequent. About $35 \%$ of the regional NRM bodies/CMAs advised that they were using these products a few times in a year (Figure 8).

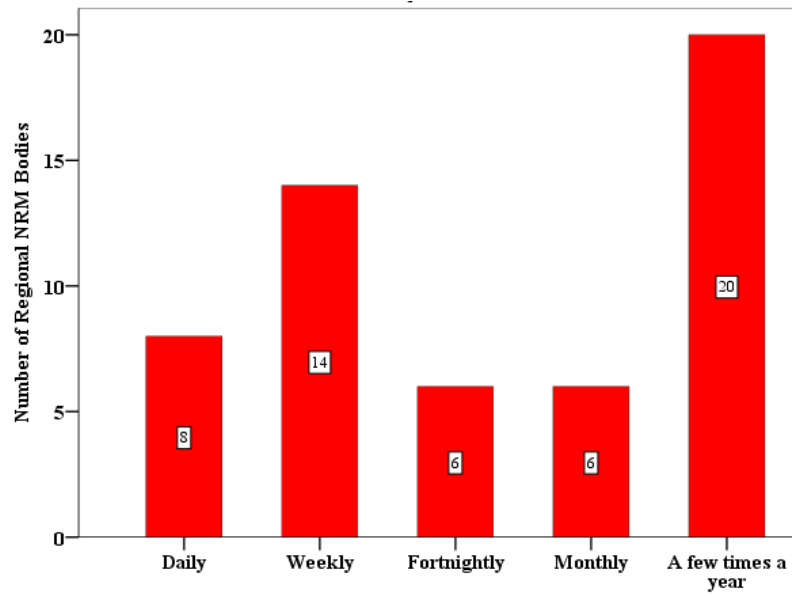

Figure 8. Utilisation of VGI and freely available/accessible spatial products for catchment management activities 
However, the level of applicability of these open source products and VGI to various catchment management issues is very high. Exchanging feedback through portals such as webblogs, facebook, flickr, twitter, etc. will be increasingly useful for community networking and exchange of ideas/knowledge. Approximately $45 \%$ of regional NRM bodies/CMAs were neutral with this statement whilst $32 \%$ of CMAs agreed with this statement. This tends to show that there is a growing recognition of utilising these new web tools and social media for spatial information sharing and exchange. The regional NRM bodies were also aware of various social networking activities and/or data sharing projects for improved catchment managements within their catchment areas.

\section{DISCUSSION AND CONCLUSION}

Spatial information plays a significant role in addressing catchment management issues and majority of regional NRM bodies agreed this statement. Regional NRM bodies are also collecting a significant amount of large scale spatial information and identified themselves as both spatial information providers and users. The main users of spatial information collected by these regional NRM bodies are the community organisations. This provides scope to support the development of spatial data infrastructure at regional level (catchment level) to address catchment management issues. Though there are disparities among regional NRM bodies regarding the catchment management issues on which they focus, we identified the top ten catchment management issues at national level. This may assist federal and state government organisations for prioritising funding and planning. We also found the catchment management issues were matched with the community-driven volunteered theme areas.

There many motivation factors for the community-driven volunteer initiatives such as Landcare, Waterwatch, Coastcare, etc. The top three motivation factors are awareness and concern regarding environmental benefits, long standing love with the land and water, and social interactions/benefits. Coleman (2010) classified the motivation of contributors into two categories as constructive and damaging. Coleman (2009) et al. summarised the construction contributions into eight categories and analysed how many of these motivations apply within VGI application. They argued that pride of place, altruism, professional or personal interest, social rewards, and intellectual stimulation are the major one. When we compared the motivation factors for community-driven volunteer initiatives and VGI applications, there were similarities. So, there is an opportunity to utilise the networks and enthusiasm of community-driven volunteer activities for spatial information collection and management.

The regional NRM bodies are aware of freely available/accessible spatial products e.g. Google Maps, OpenStreetMap, Wikimapia, etc and VGI activities and applicability of these products to various catchment management issues is very high. There is growing recognition of utilisation these new web tools and social media to contribute VGI and spatial data infrastructure development. The conceptual model developed in Figure 1 is justified through this study.
This paper has contributed to the current body of knowledge by exploring the linkage between volunteer activities and volunteered geographic information for catchment management activities and its contribution to spatial data infrastructure (SDI) development at catchment/regional level.

\section{REFERENCES}

ANZLIC, 2003. Implementing the Australian Spatial Data Infrastructure: Action Plan 2003-2004.

Axinn, W. G. and Pearce, L. D., 2006. Mixed method data collection strategies, Cambridge University Press, New York.

Carr, A., 2002. Grass Roots and Green Tape : Principles and Practices of Environmental Stewardship, Federation Press, Annandale NSW.

Clinton, W. J., 1994. Coordinating geographic data acquisition and access to the National Spatial Data Infrastructure. Executive Order 12096. Available: http://govinfo.library.unt.edu/npr/library/direct/orders /20fa.html, accessed 15 September 2011.

Coleman, D., 2010. Volunteered geographic information in spatial data infrastructure: An early look at opportunities and constraints In Spatially Enabling Society: Research, Emerging Trends and Critical Assessment (Eds, Rajabifard, A., Crompvoets, J., Kanantari, M. and Kok, B.) Leuven University Press, Leuven, Belgium, Leuven.

Coleman, D. J., Geogiadou, Y. and Labonte, J., 2009. Volunteered Geographic Information: The Nature and Motivation of Produsers, International Journal of Spatial Data Infrastructures Research, 4 (1), 332358.

Elwood, S., 2008. Volunteered geographic information: key questions, concepts and methods to guide emerging research and practice, GeoJournal, 72 (3), 133-135.

Feeney, M.-E. F., 2003. SDIs and Decision Support In Developing Spatial Data Infrastructures From concept to reality (Eds, Williamson, I. P., Rajabifard, A. and Feeney, M.-E. F.) Taylor \& Francis, London, UK pp. 195-210.

Goodchild, M. F., 2007. Citizens as voluntary sensors: Spatial data infrastructures in the world of Web 2.0, International Journal of Spatial Data Infrastructure Research, 2, 24-32.

Goodchild, M. F., 2008. Commentary: whither VGI?, GeoJournal 72, 239-244.

Gore, A., 1998. The Digital Earth: understanding our planet in the 21 st century. Digital Earth, Wikipedia. Available:

http://en.wikipedia.org/wiki/Digital_Earth, accessed 15 September 2011. 
Kuhn, W., 2007. Volunteered Geographic Information and GIScience. Paper presented at the Position Paper for the NCGIA and Vespucci Workshop on Volunteered Geographic Information, December 13-14, 2007, Santa Barbara, CA.

Longley, P. A., Goodchild, M. F., D.J., M. and Rhind, D. W. E., 1999. Geographic Information Systems In Second Edition John Wiley \& Sons, New York.

Masser, I., 2005. GIS Worlds, Creating Spatial Data Infrastructures ESRI Press, Redlands,California.

McDougall, K., 2010. From Silos to Networks - Will Users Drive Spatial Data Infrastructures in the Future? Paper presented at the FIG Congress 2010: Facing the Challenges - Building the Capacity, 11-16 April 2010, Sydney, Australia.

McDougall, K. and Rajabifard, A. (Eds.), 2007. A MixedMethod Approach for Evaluating Spatial Data Sharing Partnerships for Spatial Data Infrastructure Development, ESRI Press Redlands, California, USA.

Paudyal, D. R. and McDougall, K., 2008. Building Spatial Data Infrastructure to Support Sustainable Catchment Management. Paper presented at the Queensland Spatial Conference 2008, 17-19 July, 2008 Gold Coast, Queenslands.

Paudyal, D. R., McDougall, K. and Apan, A., 2009. Building SDI Bridges for Catchment Management In Spatial Data Infrastructure Convergence: Research, Emerging Trends, and Critical Assessment (Eds, van Loenen, B., Besemer, J. W. J. and Zevenbergen, J. A.) Netherland Geodetic Commission (NGC), Delft, The Netherlands, pp. 265-279.

Paudyal, D. R., McDougall, K. and Apan, A., 2011. Assessing Spatial Information Access, Use and Sharing for Catchment Management in Australia. Paper presented at the Spatial Sciences \& Surveying Biennial Conference 21-25 November 2011, Wellington, New Zealand.

Rajabifard, A., Feeney, M.-E. F. and Williamson, I., 2003. Spatial Data Infrastructures: Concept, Nature and SDI Hierarchy In Developing Spatial Data Infrastructures: From Concept to Reality (Eds, Williamson, I., Rajabifard, A. and Feeney, M.-E. F.) Taylor \& Francis, London, UK, pp. 17-40. 